\title{
Practice of social education of children and teenagers by Stanislav Teofilovich Shatsky
}

\author{
Valentina Davydenko ${ }^{1}$, and Nadezhda Yudina $^{1}$ \\ ${ }^{1}$ Department of Pedagogy, Pacific National University, Khabarovsk, Russia
}

\begin{abstract}
Significant changes taking place in society in connection with the pandemic are radically changing the global educational space and social reality. The transition to the distance learning model makes us look for new learning technologies, with the widespread use of it-tools. To some extent, they provide the process of transmitting and mastering information, but they do not solve a set of educational tasks. Participants in the pedagogical process are separated from each other, which ultimately leads to the loss of communication skills or their deformation. This circumstance prompted the authors to analyze critically the legacy of Russian pedagogy, addressed to the problems of social education. The article presents the results of the analysis of the theoretical and practical heritage of social education of the prominent Russian teacher Stanislav Teofilovich Shatsky $(1878-1934)$. Based on the study of the teacher's works and archival materials, the authors identified and formulated the conceptual provisions of the theory of social education S. T. Shatsky and described the main events of his practiceThe originality of this research lies in the fact that the experience of S. T. Shatsky is presented as a pedagogical technology; the authors conclude that it is possible to use historical experience in modern conditions. According to the authors, the authenticity of historical experience and modern educational practice can be achieved thanks to the general principles of education that follow from the law of natural conformity of the pedagogical process. The authors used methods of historical analysis of pedagogical heritage, systematization of theoretical positions, conceptualization and construction of pedagogical technology.
\end{abstract}

\section{Introduction}

Modern education at all its levels is undergoing profound changes. The process of permanent renewal follows two models: transformation and modernization. The first reflects ontological changes of civilizational nature and leads to a radical change in all levels of education, first of all-the goal. The second involves a partial change in the existing system based on historically formed ideas about the role of education, its purpose, goals, nature of relations, etc. As part of modernization, a creative reinterpretation of the achievements of the past becomes constructive.

Below we will present the experience of organizing the process of socialization of children, formed in Russian pedagogy at the turn of the XIX-XX centuries. The appeal to the past is justified as follows. During this period, there was a change of educational 
paradigms throughout the entire space of European pedagogy and its transition from the school of study to the school of development; Russian pedagogy was a local manifestation of the trends that swept Europe; the pedagogical tasks that arose at that time were in tune with the current ones, and their solutions contain constructive experience for us.

\section{Literature review}

S. T. Shatsky is one of the most famous Russian teachers of the pre-Soviet and Soviet periods. Interest in his work is heterogeneous. It is known that the legacy of the prominent teacher was especially actively studied during the years of Perestroika and reform of Russian education (the $80 \mathrm{~s}$ and $90 \mathrm{~s}$ of the XX century), when new strategies for the upbringing and education of children and teenages were developed. Researchers - historians of pedagogy determined the place of S. T. Shatsky in the cultural and social space of the early XX century $[2 ; 11]$, proved the experimental nature of S. T. Shatsky 's activity [11], described his experience as a pedagogical system [8; 9], evaluated the contribution of S. T. Shatsky to the development of the theory of social education [10].

In the following years, interest in the legacy of S. T. Shatsky is remained; the aspect approach was also preserved. However, today researchers identify the influence of sociocultural factors on the formation of S. T. Shatsky as a researcher $[14 ; 18 ; 19]$, the uniqueness of the teacher's activity in comparison with prominent Russian and foreign teachers $[1 ; 12]$, the contribution to the development of environmental pedagogy [13; 17], preschool education opportunities [7], the use of the heritage of S. T. Shatsky and his contemporaries in the process of training teachers $[3 ; 4]$.

The analysis of the presented literature showed that the experience of S. T. Shatsky from the standpoint of the technological approach is not described, and conclusions regarding the replication of technological elements are not made. The possibility of using the experience of S. T. Shatsky to eliminate the difficulties of developing or forming social competencies of young people excluded from direct communication in distance education is not evaluated. So, we raise a number of problematic questions: does the legacy of S. T. Shatsky contain elements of pedagogical technology? So, we pose a problem: can the historical and pedagogical heritage contain important experience for modern education? Can the historical experience of Russian pedagogy be used to minimize the risks of distance learning?

\section{Methodology}

The empirical base of the research consists of archival materials and original texts of Russian teachers of the last century; specifically, S. T. Shatsky (1878-1934), A. U. Zelenko(1871 - 1953), and L. K. Schleger (1863 - 1942).

The research methods are the analysis of pedagogical literature and archival documents, description, systematization of theoretical positions and practical solutions, conceptualization, and construction. Together they have made the experience of S. T. Shatsky as teaching the unity of conceptual and procedural decisions, to make a conclusion about the possibility of transferring the experience of the past in a different historical context.

The sequence of presentation of the material is as follows: we will reveal the pedagogical views Of S. T. Shatsky, describe some episodes of his activity, and formulate the key characteristics of the created educational system in accordance with the structure of pedagogical technology. 


\section{Main results}

The source that fueled the search for S. T. Shatsky was acute dissatisfaction with the modern school, and the impulse that prompted him to become active was a meeting with A. U. Zelenko and L. K. Schleger who developed ideas for raising children, uniting them in a community [17].

S. T. Shatsky considered education as a specially organized amateur activity. So he understood the self-organization of the educational community:"... and in this formation one does not need to stop halfway. It is necessary to lead all students so that they do all the work - both mental and physical - themselves. It is necessary that children create their own lives" [15. P. 262]. The purpose of education is to "teach life" - to ensure the socialization of adolescents and children from the lower social classes. The main means of education, according to teachers, should be a community of adults and children. In it, everyone has the same rights, but different responsibilities: educators should be members of the community, like children, but they should regulate the common life, study it, introduce new and new means of education, while maintaining a hidden pedagogical position. System-forming for the community, considered S. T. Shatsky. are "informal labor and social beginning" [16. P. 80]. S. T. Shatsky wrote: "The labor foundation helps to develop children's abilities" [22. P. 11]. Work is only the basis of work, it is supplemented by play, communication, art, raised to the level of creativity.

So, S. T. Shatsky considered education as an organized amateur activity of children, in the process of which they were enriched with the cultural heritage of humanity, and development.

The practical activity of S. T. Shatsky began in 1905, when he and A. U. Zelenko organized a dacha in Shchelkovo for children of the Sushchevsky guardianship (in the terminology of those years - a colony).

The goal that the teachers set for themselves was to show children the possibility of a "healthy lifestyle", to provide them with a reasonable rest in a country camp. The formation of a new business is described by S. T. Shatsky in the article "Children-workers of the future", published as a separate booklet in the library of free education in 1908, and is reflected in archival documents [26;27].

The pedagogical idea was to make children feel like managers of their lives, to create a circle of people who unite in a community in the process of joint work and communication.

As the materials show, first impressions were encouraging, but it soon became clear that the initial settings require adjustment. First, the teachers dreamed of conscious independence of children, but it was impossible to achieve this without the help of adults. Second, the children did not want to take responsibility for themselves, for their work, for each person's responsibility to themselves and to the community; a certain attitude to the negative aspects of life both in the country camp and outside it.

The difficulties were found also related to the fact that teachers initially did not set a clear goal for themselves, but were guided by the general idea of cultural settlement, popular at that time, which had to be filled with pedagogical content. In other words, the idea required "technologization" - the search for practical solutions.

And they were found in the activities of the pedagogical society "Settlement" (1905 1909). Its leaders wanted to create a type of "cultural center" "that would be dominated by the spirit of "family-moral". We have restored the history of the Settlement based on archival documents $[26 ; 27 ; 28 ; 29]$.

Initially, a small initiative of employees of the City guardianship of the poor of the Sushchevskaya part of the second section, who set up a shelter for incoming children at their modest means, found financial support among the residents of Moscow. So pedagogical community appeared, which took care of the maintenance of the shelter. 
Gradually, there was such a structure of educational institutions under the Settlement: clubs for children and teenagers, which received the official name of shelters for incoming children, a kindergarten, a school, craft courses, workshops, and a summer colony.

The main link was the clubs. Each club was subject to its own Charter, the highest body was the General meeting. The staff (teachers) who supervised the club had purely advisory functions: they could explain difficult issues of the organization, help to adopt the existing rules in the club. The existence of clubs was determined by the guiding idea: to enrich the lives of children with serious interests appropriate to their age; to include them in reasonable activities and entertainment; to form an experience of self-organization. The latter was achieved by including children in a joint discussion of emerging and future cases. Acting in this format, adults imperceptibly and simply forced children to think about many things, formed the habit of good and trusting relationships. According to the teachers, the space for children's initiative was supposed to serve as a "precious guarantee" for maintaining the connection of pupils with the outside world, which in General served as an impulse for their social development. At the beginning of 1907, A. U. Zelenko raised the issue of workshops where children and teenagers could be taught the craft. Students were happy to attend them; later, craft courses were created on their basis. Both workshops and craft courses implemented the apprenticeship model, allowing children from the lower social classes to find a profession. At the same time, a kindergarten and a school are opened at the Settlement. The organizers sought to distract children from the harmful influence of the street from an earlier age and make it easier for mothers to take care of them, while at the same time wanting to explore the impact of kindergarten as a preparatory stage for primary school.

As for the school, it was intended to test the possibility of applying the "active methods" already introduced in primary schools in Europe and America, while maintaining the curriculum adopted in urban primary schools. They opposed the "head" training, "uncharacteristic of the child's nature" [20. L. 53]. S. T. Shatsky wrote: "The methods are new and unusual for many viewers who are not familiar with the huge progress that has now been made by teaching in Western Europe and America, where the teaching methods used in Russian schools have long been modified and improved" [29. L.49]. The society saw its mission as promoting a learning system that was "practical, simple" and free of"routine".

Teachers constantly monitored the activities of the clubs, made interesting suggestions, raised acute problems for discussion, and at pedagogical meetings discussed the possibility of a creative attitude to the activities of the entire community. It was noticed that the life of children's clubs is different, but in General it is more meaningful where the teacher minimized his explicit participation: "We do not value external order, we value it more if a live meaningful social spark is visible in the surrounding disorder" [26. L.6].

The plan was being refined. Here are the main conclusions that determined the choice of pedagogical tools.

Teachers drew attention to the fact that children influence each other more than their elders do. Adults will not achieve success without the authority of "knowledge, experience and love for children" [29. L. 30].

In the educational community of adults and children, all functions should be differentiated according to the knowledge and experience of participants. Children will be able to create a community themselves, but only with the help of adults, children's Amateur activities should be organized and strengthened by adult activities.

Communication is an important pedagogical tool, but it can't be the only one. It should occur in activities, so children should be given the opportunity to participate in joint activities of different content: work (in accordance with the realities of the time - mainly 
physical), sports and other activities. Together, they must meet all the social needs of a growing person.

Labor is recognized as an important system-forming tool. It should become both a pedagogical tool, and an object of development, and a fundamental basis for common life. The teacher wrote: "Each skill is accompanied by technology, familiarity with the material and drawing; from this side, work touches the library; another contact of the workshop with the general life of the house through art. In my opinion, things should not be ordinary everyday rough things, but together with ornaments, ornaments, coloring, etc." [21. L. 134.].

The third technological element is art, and more broadly, creativity. Creativity For S. T. Shatsky "is the creation of a new, unprecedented from existing impressions" [22. L. 17] and is characteristic of both any person and the process as a whole, if it is by its nature a developing process, and not a cyclical repetition of frozen forms. The highest level of creativity is the creation of yourself from the material contained in yourself.

And, finally, in the club "truly children's should be given a real place" [23. L. 8]. Such a truly children's component should be a game. S. T. Shatsky introduced imitation roleplaying games into educational practice, which required a high level of activity, creativity, and self-organization from participants.

The settlement lasted until 1909 and was closed by the city authorities for political reasons. An administrative act could not destroy the idea of raising children by organizing their life activities. In the same year, 1909, the society "Child labor and recreation" was created (it existed until 1917), which continued to implement previously developed installations. Over time, "Child labor and recreation" restored all the structural links that were in the Network, and grew into a union of professional teachers who implement the ideas of new pedagogy in various educational institutions. There is a new direction of pedagogical work-generalization of practical results. The result of studying the "children's question" was the theory of club work with children. Answers were found to questions about what a club is, what principles and grounds it exists on, what its educational capabilities and significance are. The teachers came to the conclusion that the club is an open - type educational institution that unites children who are aware of their lack of social experience on a free voluntary basis. The club should organize diverse activities that allow children to "learn about life". This implies, first of all, the formation and development of the individual. A mandatory condition and means of education should be transformative activities aimed at both the environment and the individual. The teacher should lead children along the path of "social culture", guided by the nature of children and knowledge of the individuality of children. Thus, in the concept of S. T. Shatsky again asserts the thesis that education is an organized self-education of the individual, carried out by it in activities and communication in conditions of joint organized living of life.

So, we have presented the pedagogical ideas and experience of one of the most famous Russian teachers - Stanislav Teofilovich Shatsky. His work was no less resonant than the experience of internationally recognized contemporaries: S. Frenet, P. Robin, M. Montessori, D. Dewey.

We have raised a number of questions that we want to answer based on the facts presented. First of all, we are interested in whether S. T. Shatsky's legacy contains elements of pedagogical technology. We proceed from the fact that pedagogical technology is a specially organized system of educational and educational tools, theoretically and conceptually justified. The features of pedagogical technology include conceptual certainty and the presence of a pedagogical goal; the ability to diagnose the pedagogical result, consistency, manageability; effectiveness;.reproducibility.

We have shown the conceptuality above when describing the historical experience, and we do not consider it possible to repeat the formulated provisions. 
The goal of the educational system is to form social experience in children and adolescents. Experience implies the presence of cognitive, activity, and value components. The cognitive component of the S. T. Shatsky system consists in the development of students ' knowledge about the norms of life in the community; knowledge about themselves as a member of the community, knowledge of ways of organization and selforganization in the community. The activity component consists in the practical development of self-organization methods. The value component consists in awareness and understanding of the role of the social whole in the life of a person and the person - in the life of the social whole. The formation of experience and each of the components can be recorded by various diagnostic methods. S. T. Shatsky used observation and analysis of the behavior of pupils.

System. All components of S. T. Shatsky's pedagogical system are a system with clearly visible structural connections. The space for implementing a pedagogical goal is a community (in the experience Of S. T. Shatsky - clubs). These are primary associations of teachers and pupils who were subjected to pedagogical influence and correction. Within the primary community, all technological elements were implemented: self-government, work, and play. Their implementation was both purposeful and spontaneous at the same time. Purposefulness is related to the fact that the activity was carried out within the framework of the strategic plan of teachers, and spontaneity was determined by the nature of the situation.

Manageability. This feature is partially disclosed above, as it meets the requirements of systematic pedagogical technology. Emphasize that the life of each club - the primary community - was directed by adults. The degree of pedagogical intervention in the life of the children's association was regulated by the principles of hidden pedagogical position (an adult does not have the right to authoritarian pressure, his advice can be of a recommendatory nature), organized freedom of pupils (pupils themselves determine the content of their activities and organize it; an adult helps to find the optimal solution. This corresponds to the content of the pedagogical plan); the principle of creativity (permanent search for new pedagogical solutions).

The effectiveness of the technology of social education has been proved by the longterm activity of S. T. Shatsky.

Reproducibility. It is possible to draw a conclusion about whether S. T. Shatsky's pedagogical technology has such features only taking into account how pedagogical experience is spread. We believe that any pedagogical system contains elements that can be transferred to new historical, cultural, and pedagogical conditions, and elements that cannot be replicated [18]. The second group includes those that are colored by the personality of the author of pedagogical experience. We believe that all the key components of S. T. Shatsky's pedagogical system can be reproduced or form the basis of the author's pedagogical search.

So, we found signs of pedagogical technology in the experience of S. T. Shatsky and our identification of it as a technology of social education is justified.

\section{Discussion}

(?)Other questions that we have raised remain unanswered: can the historical and pedagogical heritage contain experience that is important for modern education? Can the historical experience of Russian pedagogy be used to minimize the risks of distance learning? We believe that they are of a debatable nature and can be proposed for discussion. As part of a possible discussion, we will express our positions. In our opinion, any historical experience can be useful, but it requires a delicate attitude. It should not be absolutized, since it was developed in a specific context and under the influence of specific 
historical factors [18]. We consider that it is correctly to discuss the completeness of its transfer to the new conditions. Today, they are largely determined by the course of the pandemic and the popularity of it-techniques and technologies. Risks generated by circumstances concern both the individual and the population as a whole. Among them the destruction of familiar social ties, a radical change in communication models. Under the given conditions, the teacher must use all available means to support the experience of social relations in his students. The technology of social education of S. T. Shatsky provides great opportunities for this. First of all, the creation and organization of the primary community. In our conditions, this can be micro-groups created by the teacher to solve short-term educational tasks (project development, creation of a joint product, etc.). in the learning process, the tasks set determine the content of the "work" component, in the terminology of S. T. Shatsky. Creating your own system the teacher had in mind subject work; in the current conditions, we are dealing with educational work; our task is to turn it into productive work. In other words, tasks should encourage creativity, improvisation, and going beyond learning interaction. Thus, the technology of S. T. Shatsky acquires a framework character, and its specific expression is determined by the teacher. This approach will allow us to preserve the attitude to It technologies as tools, the use of which is subordinated to pedagogical expediency.

\section{Conclusion}

As we have shown above, in the educational system of S. T. Shatsky there are two compositional cores: conceptual and procedural. The concept justifies the pedagogical tools that were developed in a long-term practical search and provides a solution to a set of tasks in the field of social education. Like any technology, the experience of S. T. Shatsky contains replicated elements that are transferred to a different historical or social space. This concerns, first of all, the principles of creating a pedagogical community and the systematic use of the pedagogical tools described above. The technology can be used to solve educational and educational tasks, but its components must be filled with content determined by the pedagogical intent.

We believe that the experience of S. T. Shatsky requires further study, and the possibility of its use in modern socio-historical conditions is discussed by the pedagogical community. The authors describe the experience of a prominent Russian teacher of the XX century as a multifunctional pedagogical technology for the first time, and the conclusion about the possibility of its use in distance education reflects a new perspective on the study of historical and pedagogical heritage.

\section{References}

1. E. N. Astafieva D. Dewey and S. T. Shatsky: meeting and acquaintance of two outstanding teachers of the XX century // Historical and pedagogical journal, 2016, no. 4, P. 64-76.

2. B. M. Bim-Bad Pedagogical trends in the early twentieth century: lectures on pedagogical anthropology and philosophy of education / B. M. BIM-bad. - M.: urao, 1998. - $114 \mathrm{p}$.

3. V. A. Davydenko Competitive University teacher - an important subject of higher school development // Materials of the National scientific and practical conference "Strategic guidelines for the development of higher education", Moscow: RUSAINS, 2019. P. 172-178. 
4. V. A. Davydenko Immersion in activity through the interpretation of activity in pedagogy//Materials of International scientific-practical conference "Education in the modern world - new contexts - new solutions", Khabarovsk: publishing house of Khabarovsk state medical.Univ. P. 67-71.

5. A. U Zelenko, L. K. Slager, E. A. Fortunatova. A. A. Fortunatov, The syllabus in primary school, developed on the basis of programs of American schools. - M.: Kushnerev, 1911. 16 p.

6. A. U. Zelenko. Methods of work in the elementary school of North America and Western Europe in application to the Russian elementary school.- M.: D. I. Sytin, 1909. - 44 p.

7. E. A. Knyazev Stanislav Shatsky and the formation of preschool education / / Preschool education. 2018. no. 8. Pp . 87-96.

8. G. I. Malinin. On the history of the Moscow society "Settlement" // Soviet pedagogy. 1985. - No. 4. - P. 105-113.

9. G. A. Malinin, F. A. Fradkin. Educational system of S. T. Shatsky. - Moscow: Prometheus, 1993. - $176 \mathrm{p}$.

10. M. V. Mikhailova. Public pedagogical and educational organizations in prerevolutionary Russia. - M.: Itpimio, 1993. - 163 p.

11. A. A. Romanov. Experimental pedagogy of the first third of the twentieth century. M.: School, 1997. - 304 p.

12. N. V. Semenova. A. S. Makarenko and S. T. Shatsky on the problems of the relationship between the individual and society // Historical and pedagogical journal, 2014. No. 4. P. 128-138.

13. N. V. Solovyova, S. T. Shatsky-the Creator of the Russian "pedagogy of the environment" // Acmeology, 2016. No. 3 (59). P. 87-96

14. L. A. Stepanova. S. T. Shatsky in the mirror of spiritual searches of the XX century // Pedagogy, 2009. no. 1. Pp . 115-121

15. S. T. Shatsky. Years of search / / Selected books. essays. - M.: State. Uch-PED. Izdatvo Min.prosv. RSFSR, 1958. P. 109-264. P. 262

16. S. T. Shatsky. Children - workers of the future / / Selected PED. works - M.: State. Uch.-PED. Izd-vo Min.prosv. RSFSR, 1958. P. 27-80.P. 80

17. N. P. Yudina. To the origins of the children's and youth social movement in Russia: "public work" by S. T. Shatsky // World of education-education in the world, 2008. No. 3. P. 57-66.

18. N. P Yudina. Development of the humanistic democratic tradition in Russian pedagogy (the 70s of the XIX century-the beginning of the XX century). - Khabarovsk, 2002. $184 \mathrm{p}$.

19. Yudina N. P. Socialization and individualization of the child in the democratic pedagogical tradition of the turn of the XIX-XX centuries // The historical experience of the development of education and pedagogy: a collective monograph / under the editorship of G. B. Kornetova. - M.: ASOU, 2015. P. 270 - 285.

20. The scientific archive of the Russian Academy of education. Fund 1. inventory 1. units HR. 4.;

21. Fund 1. inventory 1. units HR. 7., L. 134

22. Fund 1. inventory 1. units HR. 14.p. 11

23. Fund 1. inventory 1 . units HR. 16. L. 8 
24. Fund 1. inventory 1. units of HR. 60. L. 49

25. Fund 1. inventory 1. units of HR. 4, L. 53

26. Fund 1. inventory 1. units of HR. 57; .

27. Fund 1. inventory 1. unit HR. 58.;

28. Fund 1. inventory 1. unit HR. 59;

29. Fund 1. inventory 1. units HR. 60. 